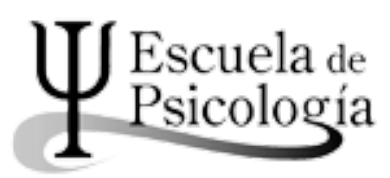

Wímblu, Rev. estudiantes Esc. de psicología, Univ. de Costa Rica. 12 (2): 101-115, 2017 / ISSN: 1659-2107

\title{
La verdad y la mentira en el recuerdo y el olvido
}

Thruth and lie in memory and oblivion

Marcelo Novas ${ }^{*}$

Resumen: Este artículo pretende trabajar la dimensión clínica del olvido y la memoria, a partir de las propuestas de Freud y Nietzsche, en relación a la compulsión a la repetición y al eterno retorno respectivamente. El objetivo es aportar insumos para pensar las actuaciones en la tarea clínica.

Palabras clave: psicoanálisis, olvido, verdad.

Abstract: This article intends to work the clinical dimension of oblivion and memory, from the proposals of Freud and Nietzsche, in relation to the compulsion to the repetition and to the eternal return respectively. The objective is to provide inputs to think about the performans in the clinical task.

Key Words: Psychoanalysis, oblivion, truth.

Facultad de Psicología de la UdelaR. Docente e investigador. Uruguay. Correo electrónico: mnovas@psico.edu.uy

Recepción: 17/7/2017 Aceptación: 4/10/2017 
Recuerdo y olvido, verdad y mentira son tópicos que tanto Sigmund Freud como Friedrich Nietszche han abordado a lo largo de sus obras. En las siguientes líneas trataremos de mostrar de qué forma estas temáticas fueron planteadas por estos autores, a la vez que intentaremos proponer una lectura no excluyente de estos últimos. Esto en la medida que entendemos que la tarea analítica se verá enriquecida en tanto podamos poner a discutir algunas ideas que podrían aparecer como antagónicas cuando en realidad no lo son. Fundamentalmente se buscará discutir la idea del olvido como una dimensión negativa de la subjetividad, para lo que utilizaremos como guía una afirmación de Jacques Lacan: 'El olvido freudiano es una forma de la memoria, su forma misma, la más precisa. Él (Freud), mejor desconfiará de palabras como olvido' (Lacan, 1964-65:34).

\section{Freud y Nietzsche}

No son más de quince las veces que aparece nombrado Friedrich Nietszche en las obras completas de Sigmund Freud publicadas por Amorrortu editores, y curiosamente en dos de ellas Freud refiere que decidió privarse de la lectura del filósofo. Así lo vemos en Contribución a la historia del movimiento psicoanalítico, (Freud, 1914d:15) y también en su Presentación autobiográfica (Freud, 1925d:56). En la primera de esas ocasiones alega no querer verse influido por lo que podía ser una investigación demasiado cercana a la suya, lo que puede entenderse a partir de lo ocurrido en relación al episodio que involucró a Fließ, Weininger y Swoboda en donde Freud termina acusado de plagiario. Aún otra posibilidad puede estar dada por como Freud trae la figura de Nietzsche en Lo ominoso (Freud,1919h:234) donde 'el permanente retorno de lo igual' dice allí Freud, aparece asociado a la figura del doble, ese 'doppelgänger' cuya aparición no auguraba nada bueno. Quizá la opción de Freud de rehusarse el elevado goce de la lectura de Nietzsche, como él mismo declara, opción eminentemente apolínea y nada dionisíaca, inauguró la distancia y el malentendido que signaría la relación de este último con el psicoanálisis. A pesar de ello, es evidente que diversos tópicos tratados por Nietzsche aparecen trabajados por Freud y sus seguidores: así tenemos el planteo de un 'ello' en donde Freud reconoce la prioridad de Nietzsche, la idea de la actividad inconsciente, y por último, la concepción del eterno retorno de lo mismo, que el psicoanálisis trabajará a partir de la noción de repetición.

Precisamente en Recordar, repetir, reelaborar (Freud, 1914g) es que la compulsión a la repetición hace su ingreso al cuerpo doctrinal del psicoanálisis, y lo hace a partir de una oposición. Dicha oposición es la que enfrenta recuerdo y repetición, en la medida que parecen ser los extremos de lo que puede ocurrir en un psicoanálisis: la rememoración, buscada y alentada por el trabajo analítico opuesta a las actuaciones, las que se buscaría evitar y que serían el vehículo de la wiederholungszwang (compulsión a la repetición). De esta forma la dimensión que se buscará abordar en este texto es la que opone el recuerdo a la actuación, en la medida que esta sería una forma de recuerdo en acto, sin pasaje por la rememoración narrada. A su vez podríamos decir que la actuación, como recuerdo en acto, aparecería como opuesta al olvido, ese olvido que permite pasar a otra cosa y aliviarnos de eso que perturba y molesta. Es en ese sentido que deseamos abordar algunas de las ideas que propone Friedrich Nietzsche en Sobre verdad y mentira en sentido extramoral en tanto podrán echar luz sobre esta problemática, particularmente en lo que refiere al olvido.

Sigmund Freud en Recordar, repetir y reeleborar (Freud, 1914g, 152) comienza por recorrer las diferentes etapas que transitó el psicoanálisis hasta ese momento y para hacerlo nos pide no olvidar las profundas modificaciones que sufrió la técnica. Y de esa forma, en ese texto, opone el recuerdo a la actuación dentro de un proceso terapéutico diciéndonos:

Cuando aplicamos la nueva técnica resta muy poco, nada muchas veces, de aque decurso de alentadora tersura. Es cierto que se presentan casos que durante un trecho se comportan como en la técnica hipnotica, y solo despues se deniegan; pero otros tienen desde el comienzo un comportamiento diverso. Si nos atenemos al signo distintivo de esta técnica respecto del tipo anterior, podemos decir que el analizado no recuerda, en general, nada de lo olvidado y reprimido, sino que lo actúa. No lo reproduce como recuerdo, sino como acción; lo repite, sin saber, desde luego, que lo hace. (Freud, 1914g: 151-52, cursivas del autor)

En este trabajo la preocupación de Freud es ubicar dentro de la cura los lugares diversos que ocupan el recuerdo y la actuación, dado que aquellos analizantes que no apelaban a las actuaciones dentro de su proceso analítico, presentaban menos dificultades en el trabajo y se podía suponer por ello, un mejor pronóstico. Hoy día, en la cotidianidad de la tarea clínica, aquellos consultantes que apelan a las actuaciones por sobre la rememoración ocupan un porcentaje destacado dentro de la población que consulta, por lo que detenernos a investigar la relación entre recuerdo, olvido y acto resultará fundamental para afrontar el encuentro analítico.

Pero la oposición entre recuerdo y acto no es la única que aparece abordada en ese trabajo, también la que ocurre entre recuerdo y olvido. Y la cuestión noda es que el olvido podía ser causa de malestar.El psicoanálisis como tratamiento del malestar de los sujetos recorrió diferentes momentos, y desde sus comienzos trató de poder teorizar sobre las causas de dicho sufrimiento. Dicho malestar podía asumir diferentes presentaciones, desde las más intensas, traducidas en lo que se entiende como enfermedad psíquica, hasta cuestiones más puntuales, aquellas que en nuestro día a día aparecen para dar cuenta de la efectividad de la actividad inconsciente, aquellas que Lacan llamó formaciones de lo inconsciente: sueños, lapsus, actos fallidos, incluso el chiste. Tan clara era para Freud esta situación, 
que dedica su Psicopatología de la vida cotidiana al estudio y presentación de esa serie de eventos que pueden conmovernos en cualquier momento de nuestra experiencia. De este manera vemos que en dicha obra trabaja sobre los actos fallidos, el trastrabarse al hablar, los lapsus linguae y calami, errores, acciones sintomáticas, y lo que me parece central para el presente escrito, sobre el olvido. Los dos primeros ejemplos de esa 'psicopatología' son ya clásicos en el campo del psicoanálisis: el primero es el olvido del nombre propio Signorelli, el segundo el olvido de la palabra extranjera aliquis (Freud, 1901b, pp.9 y 16). Lo que relaciona a estos dos olvidos es el hecho que poder recordar ambas palabras estaba impedido por el malestar que produciría traer a la conciencia los contenidos asociados a las mismas, lo que para Freud implicaba que ciertos recuerdos debían permanecer inconscientes para evitar el displacer.

No menos cierto es que el carácter de dichos eventos también llevó su discusión y proceso en el psicoanálisis, dado que Freud, que en un principio había sostenido una teoría traumática para explicar la etiología de la histeria, más tarde abandona esta idea para pasar a sostener la eficacia de la fantasía inconsciente, como le informa a Fließ en su famosa carta del 21 de setiembre de 1897, al escribirle que "ya no creía en su neurótica" (Freud, 1994:283). Entonces ¿esos eventos habían tenido lugar en la realidad o no?, ¿era verdad que habían ocurrido? Aquí lentamente comenzamos a acercarnos a Nietzsche y lo que propone en su texto. Podría decirse que en psicoanálisis la verdad como problema aparece fuertemente ligada al tema de la realidad, principalmente en la obra de Sigmund Freud. Vemos así que en uno de sus últimos textos, Análisis terminable e interminable decía: "... el vínculo analítico se funda en el amor por la verdad, es decir, en el reconocimiento de la realidad objetiva, y excluye toda ilusión y todo engaño" (Freud, 1937c, 249); como vemos, varios tópicos caros a esta disciplina se despliegan en esta breve frase: amor, verdad, realidad, ilusión. La búsqueda de Freud de una confirmación empírica de sus teorías encuentra su ejemplo más claro y dramático en el caso narrado en De la historia de una neurosis infantil (Freud, 1918b:1), popularmente conocido como 'el hombre de los lobos', donde Freud, inmerso en su polémica con Jung busca la confirmación de sus hipótesis por parte de su paciente a partir de la construcción propuesta por Freud mismo, extremo que nunca es alcanzado, más allá de la innegable eficacia de la intervención de este último. Volviendo a Análisis terminable e interminable es un escrito tardío de Freud, pero esa búsqueda de la realidad objetiva aún era una aspiración suya, por más que la había matizado ya tiempo atrás.

En este punto nos parece de orden detenernos en el salto dado desde la realidad a la realidad psíquica tal como la entiende el psicoanálisis. Digamos que ya en 1893 Freud había planteado que "el histérico padece por la mayor parte de reminiscencias" (Freud, 1893a:33) pero al abandonar la teoría de la seducción, las fantasías inconscientes (a partir de la hipótesis de la existencia de un inconsciente eficaz) pasan a poseer un valor patógeno de igual efectividad que los recuerdos traumáticos para los sujetos; será por esta razón que en la conducción de un tratamiento psicoanalítico el acento ya no recaerá en tratar de perseguir la realidad material, wirlichkeit escribirá Freud, sino en poder ubicar la eficacia de esa psychische realität, realidad psíquica, a partir del discurso de aquel que se está analizando.Para Lacan la cuestión ya toma otro cariz, quizá debido a su lectura de Heidegger, y lo que este puede transmitir sobre Nietzsche, por lo que retomará esta cuestión en la medida que entiende que la verdad en un psicoanálisis se funda en la palabra dicha en el mismo. Evidentemente para Lacan la palabra posee un valor, y ese valor puede ser de veracidad o falsedad, pero este valor no dependerá de la adecuación del discurso a la realidad fáctica del sujeto, sino de la lógica que de su discurso se desprende, como ejemplo podemos traer lo que propone en Subversión del sujeto y dialéctica del deseo:

Observemos entre paréntesis que ese Otro distinguido como lugar de la Palabra no se impone menos como testigo de la Verdad. Sin la dimensión que constituye, el engaño de la Palabra no se distinguiría del fingimiento que, en la lucha combativa o la ceremonia sexual, es sin embargo bien diferente. Desplegándose en le captura imaginaria, el fingimiento se integra en el juego de acercamiento y de ruptura que constituye la danza originaria, en que esas dos situaciones vitales encuentran su escanción, y los participantes que ordenan según ella lo que nos atreveremos a llamar su dancidad. El animal por lo demás se muestra capaz de esto cuando está acosado; llega a despistar iniciando una carrera que es de engaño. Esto puede ir tan lejos como para sugerir en las presas la nobleza de honrar lo que hay de ceremonia en la caza. Pero un animal no finge fingir. No produce huellas cuyo engaño consistiría pistacer como tampor falas siendo verdaderas, es decir las que darían la buena significante. Todo signifante. Todo esto no ha sido articulado sino de manera confusa por filósofos sin la ficción al orden del significante y que el significante exige otro lugar -el lugar del la ficcion al orden del significante y que el significante exige otro lugar-el lugar del Otro, el Otro testigo, el testigo Otro que cualquicra de los participantes- para que la lugar otro que la Realidad a la que concierne de donde la Verdadad. Asli, es de un es de la palabra Como es también de ella de quien recibe Vera marca que la instituye en una estructura de ficción. (Lacan, 1987:787, mayúsculas del autor)

No en vano Lacan le había solicitado a Heidegger permiso para publicar en el primer número de La psychanalyse, la revista de la por aquel entonces novel Sociedad Francesa de Psicoanálisis, una traducción de Logos, texto donde este último presentaba tres comentarios de fragmentos de Heráclito y de Parménides, 'Moira, Aletheia, Logos' (Roudinesco, 1994:333). La verdad, aletheia en su forma griega, remitía a develamiento, lo que puede encontrarse en el texto de Lacan citado antes, por más que luego de Platón, y sobre todo con Aristóteles había sido considerada como adequatio rei et intellectus. Más para Lacan no se trataría en un psicoanálisis de la adecuación a la realidad o a la cosa, como a veces gustaba decir. 
Llegamos así a aletheia, como los griegos llamaban a la verdad, y aún lentamente seguimos acercándonos al texto de Nietzsche. Aletheia, verdad, se opone a lethe, olvido, en la medida que la partícula privativa 'a', niega el olvido, por esta causa podríamos entender, siguiendo este razonamiento, que la verdad sería el no olvido. Esto último estaría en consonancia con el planteo freudiano que decía que el histérico sufre de reminiscencias, anamnesis; entonces, ¿la solución a dicho malestar pasaría por el olvido? Aquí es donde encontramos ese suelo común con el olvido y la memoria trabajados por ciertos abordajes psicoanalíticos, en tanto el texto de Nietzsche puede ofrecer un lugar creador para el olvido, un lugar cercano a la poiesis, y ya no un mero síntoma que denunciaría un malestar.

\section{Sobre la verdad y el olvido}

Sobre verdad y mentira en sentido extramoral es un texto que Nietzsche dictó a Carl von Gersdoff en 1873 y en el que vemos como este autor pone en práctica el análisis genealógico como para poder exponer de qué forma las ideas que utilizamos llegaron a ocupar dicho lugar en nuestro conocimiento. Elegí no decir se originaron, atendiendo a la lectura que realiza Michel Foucault de este trabajo, tal como aparece expuesta en la primera conferencia que realiza entre los días 21 y 25 de mayo de 1973 en la ciudad de Río de Janeiro y que en castellano se publicó bajo el nombre de La verdad y las formas jurídicas (Foucault, 2008:11). En ese trabajo Foucault destaca que Nietzsche, al hablar de esos animales inteligentes, dice que en un determinado tiempo y lugar del universo, inventaron el conocimiento, y lo que propone Foucault es que Nietzsche utiliza erfindung, invención, para no utilizar ursprung, origen. Foucault saluda esa decisión nietzscheana, en tanto era una actitud absolutamente irreverente y audaz por ese entonces, año 1873, pleno neokantismo, enfrentarse a los planteos de Kant y proponer que tiempo y espacio no son formas del conocimiento y que podían preexistir al mismo (Foucault ,2008:18). Y más adelante Foucault insiste:

Más aún, en La voluntad de poder Nietzsche afirma que no hay en sí, y tampoco conocimiento en si. Cuando afirma esto, designa algo totalmente diferente de lo que Kant entendia por conocimiento en sí. Nietzsche quiere decir que no hay naturaleza, ni esencia ni condiciones universales para el conocimiento, sino que éste es cada vez el resultado histórico y puntual de condiciones que no son del orden del conocimiento. El conocimiento es un efecto o un acontecimiento que puede ser colocado bajo el signo del conocer, no es una facultad y tampoco una estructura universal. Aun cuando utiliza ciertos elementos que pueden pasar por universales, este conocimiento será como mucho del orden del resultado, del acontecimiento, del efecto. (Foucault, 2008:30)

Sobre verdad y mentira en sentido extramoral es el escrito donde Nietzsche plantea una fábula, dado que los protagonistas son animales, 'animales inteligentes' dice (Nietzsche, 2004:17), pero animales al fin. ¿Cuál es el mensaje de esta fábula? Que la diferencia entre verdad y mentira es una convención, un efecto del poder legislativo de la palabra. Esto establece que no existe un fin trascendente del conocimiento, este nace y muere con la humanidad, lo que aparece gráficamente en la imagen dada al comienzo del texto cuando dice: 'Tras breves respiraciones de la naturaleza el astro se heló y los animales inteligentes hubieron de perecer' (Nietzsche, 2004:17). Entonces podemos entender que la verdad sea efecto de la condición social del ser humano; en la medida que este precisa vivir en comunidad, le resulta necesario y útil establecer una serie de legalidades y convenciones que regulen los intercambios entre los seres humanos, legalidades y convenciones que se establecerán en función de los efectos que produzcan, y quizá aquí podríamos ver cierta cercanía con la propuesta freudiana de un principio del placer que regule la actividad psíquica, principio de placer que terminará modificándose en un principio de realidad, en donde el placer se buscará ya no mediante la descarga directa, sino a través de los caminos aprendidos como para conciliar las exigencias del polo pulsional sí, pero también del mundo exterior y las exigencias culturales.

Podría decirse que en ese punto Nietzsche también es hijo de su tiempo y adhiere a la idea de un pacto que dé origen a la sociedad (lo que rápidamente nos hace pensar en el Leviatán hobbesiano) ese pacto tiene que ver con un acuerdo en relación a como nominar, como designar, lo que necesariamente se hará a través de la palabra y el lenguaje. Aquí podemos ver que para Nietzsche, en tanto la palabra, vehículo de la verdad y la mentira, es una convención, no por ello carece de valor, dado que hay una función creadora de la palabra, y esa función creadora de la palabra es precisamente el arma o herramienta de la que disponen los seres humanos: carecemos de dientes afilados, garras o cornamentas, pero disponemos del recurso del lenguaje, por lo tanto este tiene una función en relación a la vida. La función metafórica de la palabra, en tanto no busca una adecuación de la realidad a las cosas, es una función creadora, y por esa razón Nietzsche da tanta importancia al arte en la vida de los sujetos. Podríamos decir que para Nietzsche, la verdad y el arte comparten su nacimiento, en tanto parten de la tendencia creadora del ser humano, pero la gran diferencia radica en que la verdad será el campo que la ciencia buscará dominar, no a partir de las múltiples posibilidades, sino a través del reduccionismo árido que implica la utilización de los conceptos, y el arte implicaría asumir todas las consecuencias de un mundo en movimiento, donde la abstracción, el gran vehículo de la conceptualización y la ciencia, solo sería posible en tanto reducir y olvidar las diferencias. Citemos a Nietzsche:

Pero pensemos especialmente en la formación de los conceptos. Toda palabra se convierte de manera inmediata en concepto en tanto que justamente no ha de servir para la experiencia singular y completamente individualizada a la que debe 
su origen, por ejemplo, como recuerdo, sino que debe encajar al mismo tiempo con innumerables experiencias, por así decirlo, más o menos similares, jamás idénticas se forma por equiparación de casos no iguales. Del mismo modo que es cierto que una hoja no es igual a otra, también es cierto que el concepto hoja se ha formado an abandonar de manera arbitraria esas diferencias individuales, al olvidar las notas distintivas, con lo cual se suscita entonces la representación, como si en la naturaleza hubiese algo separado de las hojas que fuese la "hoja", una especie de arquetipo primigenio a partir del cual todas las hojas habrían sido tejidas, diseñadas, calibradas, coloreadas, onduladas, pintadas, pero por manos tan torpes, que ningún ejemplar resultase ser correcto y fidedigno como copia fiel del arquetipo (Nietzsche, 2004:23)

Vemos como aparece el recuerdo, experiencia singular, opuesto al olvido como operación necesaria para que el borramiento de la diferencia actúe de forma tal que la abstracción sea posible, mas la tarea de este olvido no deberá ser ocultar el origen múltiple de lo verdadero, sino permitir la creación a partir de la posibilidad de disponer y ordenar de una forma novedosa, en tanto el olvido permitiría un nuevo comienzo.A causa de esto, un poco antes en el texto, el autor había sostenido que "solamente mediante el olvido puede el hombre alguna vez llegar a imaginar que está en posesión de una 'verdad'..."Nietzsche, 2004: 21).

Quizá sería sencillo ver en esta posición nietzscheana una desvalorización o desprecio por la verdad, lo que sería una lectura apresurada. Como dijimos Nietzsche ubica el arte y la verdad a un mismo nivel, y para este autor el arte es la dimensión central y fundamental de la vida, en tanto será en un espíritu artístico donde se manifestará la voluntad de poder, además que Nietzsche no pretende desautorizar la verdad, sino darle su correcta dimensión, y precisamente será con el arte, y más particularmente la música donde buscará la respuesta.Dentro de la formación cultural de este autor la música ocupa un destacado lugar; Nietzsche es un más que correcto ejecutante de piano e incluso ensaya componer algunas piezas musicales, no obviemos además, su estrecha y tumultuosa amistad con Richard Wagner, amistad que marcará la vida y la obra de Nietzsche.Su proximidad con Wagner puede entenderse a partir de la admiración que ambos sentían por la obra de Schopenhauer, a quién podemos ubicar como el filósofo que le otorga a la música su poder transformador.Como plantea Gustavo Varela en Nietzsche. Una introducción, Schopenhauer es la voz que para Wagner y Nietzsche, aporta una alternativa a la racionalidad moderna. Si el deseo mundano es una fuente de malestar, en tanto siempre nos confronta con la insatisfacción, solo el arte nos rescatará: el soportar la vida como un deseo permanentemente insatisfecho tiene su salida en la posibilidad de la creación artística. ¿Cómo entender esto? Varela nos dice:

Lo que Nietzsche toma de Schopenhauer lo transfigura y lo lleva al extremo. Esto significa que, a pesar de la crítica que posteriormente ha de realizarle a su filosofía la clave musical que utiliza es la misma, aunque modifique la altura y la intensidad de las notas (voluntad, ya no como voluntad de vivir, sino de poder), aunque ya no sea una escala menor sino mayor (del pesimismo a la jovialidad), aunque el timbre de los sonidos sea otro (el tiempo, no como condición de la representación sino como sus conceptos y los hace modular de acuerdo con sus propias alteraciones. Esto no significa que su pensamiento sea una continuación del de aquel: Nietzsche va a ser crítico de la metafísica de la voluntad en tanto que los derivados a los que puede conducir están más cerca de la resignación cristiana que del superhombre. Decir que la clave es la misma es entender que hay una geografía sonora compartida, que Nietzsche lee sobre el pentagrama de Schopenhauer y compone su obra sobre la misma notación musical: voluntad, artista, música, genio, tiempo, guerra,vida. Son las notas con las que traza su propia melodía, alterándolas, cambiándoles su valor y su altura, obligando a la filosofía a tener otra secuencia armónica y otra intensidad. A la filosofía y a él mismo. (Varela, 2010:92)

Para poder comprender este párrafo tan condensado, entiendo que debemos sobre todo, desarrollar las ideas que aparecen entre paréntesis en el fragmento citado, es decir, a qué llama Nietzsche eterno retorno, voluntad de poder, y pasar del pesimismo a la jovialidad. Para ello nos serviremos del ensayo de Andrea Díaz Genis El eterno retorno de lo mismo o el terror a la historia. Según la autora, Nietzsche plantea tres formulaciones de su idea del eterno retorno de lo mismo: la primera estaría ubicada en La gaya ciencia, la segunda en Así habló Zaratustra, y la tercera en Más allá del bien y del mal. A los efectos del presente trabajo nos dedicaremos a lo que propone Nietzsche en Así habló Zaratustra, en tanto en ese trabajo el tema del olvido se relaciona con el del eterno retorno de lo mismo.

\section{Olvido y eterno retorno}

La idea del eterno retorno de lo mismo se le ocurre a Nietzsche casi a la manera de una experiencia mística. Andrea Díaz Genis, citando la biografía escrita por Daniel Halévy La vie de Fréderic Nietzsche, nos dice que el filósofo sintió una emoción tan intensa que sus lágrimas corrieron por sus mejillas, permaneciendo largo tiempo ensimismado en su llanto, pero más aún, Nietzsche durante algunas semanas se encuentra en un nivel de arrobamiento y angustia que permite pensar su experiencia como una experiencia mística (Díaz Genis, 2008:69). El eterno retorno de lo mismo implicaría plantearse la conjetura, permitirnos hipotetizar sobre la posibilidad que los hechos de nuestra vida, tal como la vivimos, ahora y antes, ocurriesen de manera repetitiva ad infinitum. $Y$ aquí radica la diferencia de postura de Nietzsche con planteos de tipo míticos, que podemos encontrar en la obra de Eliade (Díaz Genis, 2008:25), o como un pensamiento religioso tal como lo presenta Kierkegaard (Díaz Genis, 2008:43): para Nietzsche se trata de una cuestión ético-práctica, sesgo que Díaz Genis elige priorizar en su ensayo, eligiéndolo sobre el aspecto científico u ontológico. Pero ¿por qué ético-práctica?, porque implica apuntar a la fuerza del pensamiento como fuerza transformadora, 
implica actuar como si nuestra vida tal y como es, fuese a repetirse, y esto en tanto la voluntad de elegir que así ocurra. Sin duda en esto radica la voluntad de poder, no en un voluntarismo que elimina el acontecimiento como posibilidad, sino en el hecho de poder asumir que elegiremos que nuestra vida ocurra en relación a todas sus posibilidades, incluso aquellas que pueden no ser agradables, como, por ejemplo, puede serlo el dolor. Entiendo que aquí, en relación a lo agradable o desagradable, a lo placentero o lo doloroso, es donde se articula el olvido con el eterno retorno de lo mismo.

Giorgio Colli en su Introducción a Nietzsche nos propone que la voluntad de poder lleva consigo el dolor (Colli, 2000:140), y el tema del dolor para este autor, es un reflejo discursivo de aquel conocimiento perturbador que en Así habló Zaratustra se traduce en el tema del eterno retorno (Colli, 2000:142). Podemos relacionar con esto la tesis del olvido activo que aparece en Genealogía de la moral donde podemos leer:

Educar y disciplinar a un animal que pueda 'hacer promesas', ¿no es ésta la tarea paradójica que la Naturaleza se ha propuesto con el hombre? ¿No es éste elverdadero paradojlca que la Naturaleza se ha propuesto con el horom prado grado superior es apreciar todo vis inertiae como creen los espíritus superficiales; es más bien un poder activo vis inertiae, como creen los espiritus superficiales, es más bien un poder activo, hay que atribuir hay que atribuir el hecho de que todo to que nos sucede en la vida, todo lo que nosotros absorbemos se presenta tan pocas veces a nuestra conciencia en el estado de 'digestion' (se le podría llamar de absorción psiquica) como el proceso múltiple por que atraviesa nuestro cuerpo mientras 'asimilamos' nuestros alimentos. Cerrar de tiempo en tiempo las puertas y las ventanas al ruido y a la lucha que el mundo subterráneo de los órganos a nuestro servicio libra para ayudarse o destruirse; callar un poco, hacer tabla rasa en nuestra conciencia para que haya un nuevo sitio para cosas nuevas, y, en particular para las funciones más nobles, para gobernar, para prever, para presentir (pues nuestro organismo es una verdadera oligarquía): he aquí, repito, el papel de la facultad activa de olvido, una especie de guardián, de vigilante encargado de mantener el orden psíquico, la tranquilidad, la etiqueta. De aquí concluiremos inmediatamente que ninguna dicha, ninguna serenidad, ninguna esperanza, ninguna fiereza, ningún goce del 'instante presente' podrían existir sin la facultad de olvido. El hombre en quien este aparato de inhibición está estropeado y no puede funcionar es semejante a un dispéptico (y no solamente semejante): no consigue ya llevar nada a buen fin... iPues bien! Este animal, necesariamente olvidadizo, para el que el olvido es una fuerza y la manifestación de una salud 'robusta', se ha creado una facultad contraria, la memoria, por la cual, en ciertos casos, tendrá en jaque al olvido , a saber, en los casos en que se trata de prometer: no se trata, en modo alguno, de la imposibilidad puramente pasiva de sustraerse a la impresión, una vez recibida ésta, o del malestar que causa una palabra una vez empeñada y de la cual no nos podemos desligar, sino de la voluntad activa de guardar una impresión, de una continuidad en el querer, de una verdadera 'memoria de la voluntad': de suerte que, entre el primitivo 'yo haré' y la descarga 'memoria de la voluntad': de suerte que, entre el primitivo 'yo haré' y la descarga nuevas $y$ extrañas $y$ aun de actos de voluntad, puede colocarse sin inconveniente y sin que se deba temer ver ceder bajo el esfuerzo esta larga cadena de voluntad. Pero icuántas cosas hace suponer esto! Para poder disponer así del porvenir, el hombre ha tenido que aprender a separar lo necesario de lo accidental, a penetrar la causalidad, a anticipar y a prever lo que oculta lo lejano, a saber disponer sus cálculos con certidumbre de manera que pueda discernir el fin de los medios, y ha tenido que comenzar por hacerse 'apreciable, regular, necesario', para los demás responder de su persona

La extensa cita se justifica si tomamos en cuenta lo que propone Pierre Klossowski sobre el olvido y el eterno retorno en Nietzsche y el círculo vicioso, en tanto el olvido permite el 'descubrimiento' del sujeto en la medida que es el olvido el que permite ocultar el devenir eterno y la absorción de todas las identidades en el ser (Díaz Genis, 2008:102) ¿Qué quiere decir esto? Esto implica que es el olvido el que habilita el pasaje por la experiencia del eterno retorno, pero, ¿de qué manera? En el momento que el sujeto pasa por el brusco despertar al modo de una Stimmung, del eterno retorno, ocurre un sutil develamiento (Klossowski, 2005:64) ese sutil develamiento es que le fue revelado que ahora es otro, y si ahora es otro, quiere decir que esa posibilidad existe en tanto puede y pudo olvidar esa antigua identidad ( $y$ en este punto resuena verdad como develamiento, aletheia). Queremos aquí recordar la lectura de Gianni Vattimo sobre el eterno retorno: "el eterno retorno no puede ser, de ninguna manera, una estructura objetiva y esencial de la realidad que estamos obligados a aceptar" (citado en Díaz Genis, 2008:103), evidentemente la lectura de Vattimo, se apoya en que "no existen hechos, sólo interpretaciones" tal como plantea Nietzsche en La voluntad de poder (citado en Díaz Genis, 2008:103). Un poco antes hablamos del devenir y deberíamos detenernos en cómo piensa Nietzsche la relación entre el ser y el devenir para echar algo de luz a este tema.

Nietzsche frente a este dualismo, que podemos remontar hasta el debate entre Parménides y Heráclito, toma partido claramente por el de Efeso frente al eleata, en el sentido que entiende el devenir como lo único real, es decir, como interpretación verosímil (Díaz Genis,2008:89), pero a la vez trata de pensarlos simultáneamente, lo que supone a la vez, cierta simultaneidad de Aión y Cronos, en el sentido que en el instante de la vivencia del eterno retorno, el tiempo y la eternidad se encuentran, lo que aparece graficado en la primera de las dos visiones que tiene Zaratustra, la que muestra la metáfora de los caminos y el portón del instante, donde el tiempo aparecería con cierto carácter de circularidad, pero esta primera visión es completada y superada con la segunda, la que muestra al pastor y la serpiente: sólo en el momento que el pastor decide- y en esta decisión está la clave- morder la serpiente, implica un corte, y aceptar que así fue querido, para de esa forma no quedar atrapado en los ciclos repetitivos. Entendemos que en este punto podemos articular que es el espíritu dionisíaco aquel que es capaz 
de unir la eternidad y el tiempo, el ser con el devenir, y por ese motivo no puede aceptar la voluntad de vivir como la entendía Schopenhauer, razón por la que propondrá como alternativa la voluntad de poder, lo que leemos como el pasaje del pesimismo, o nihilismo pasivo, a la jovialidad, a una afirmación de la vitalidad que encuentra su máxima expresión en la sentencia amor fati. Para Nietzsche este es el lugar que precisa de un espíritu creador, de un espíritu artístico, para a partir de la invención, de lo creativo afirmarse en la existencia. Para Schopenhauer la voluntad de vivir supone la necesidad de liberarse, de manera ascética, del deseo perturbador, en tanto este es ausencia, insatisfacción y sufrimiento. Nietzsche se opone a este planteo y propone una voluntad de poder que se afirma en la creación como alternativa al dolor, no para negarlo, sino para poder hacer con él de otra manera, ahí radica el amor fati en relación al eterno retorno, en la afirmación de desear la vida en todas sus dimensiones y posibilidades. Para poder lograr esto, el espíritu humano debe sufrir tres transformaciones, dice Nietzsche en el primer discurso de Zaratustra: primero es camello, aquel agobiado por el 'tú debes' que responde a la imagen del otro que debemos soportar como una carga; luego es león, caracterizado por el 'yo quiero', pero el león grita en el desierto, su soledad contrasta con la del camello, animal de caravanas y mercados, el león, la segunda transformación prepara la tercera, es decir, el niño, en tanto "sólo el niño es capaz de un santo decir sí, inocente; es el único capaz de olvido necesario para que cada decisión del eterno retorno sea plena, renovada" (Díaz Genis, 2008:106, cursivas de la autora). El león, con su soledad, prepara la inocencia del niño, y lo prepara para ser un creador, en la medida que el peso de la historia es diferente para el niño, no tiene la carga del 'tú debes', ni el peso del resentimiento o la mala conciencia. Aquí podría leerse que el superhombre nietzscheano, es un niño que juega, imagen que nos remite a los fragmentos de Heráclito, pero a la vez al juego planteado por el psicoanálisis como una forma que tiene el niño de aprender a tramitar la angustia, tal como Freud nos plantea en Más allá del principio del placer (Freud, 1920g: 1).

\section{Una propuesta desde el psicoanálisis}

Esta transformación, este movimiento quizá no esté lejos de la definición de salud mental ensayada por Jean Allouch en su ensayo Letra por letra donde frente a la pregunta sobre cómo definía a la misma, propone la sentencia 'pasar a otra cosa' (Allouch, 1993:9 cursivas del autor). Este pasaje donde lo creativo es condición necesaria, pero creación del sujeto que debe volverse artífice de sí mismo, no está lejos del olvido como capacidad creadora. En El sexo de la verdad, el mismo Allouch nos habla sobre el malentendido que padeció el psicoanálisis en torno al olvido, al confundir el análisis con la búsqueda de lo olvidado, el recuerdo perturbador, cuando de lo que se trataba era tramitar aquello que no podía olvidarse, para lo que el olvido no era una mala estrategia. Pero recordemos que el olvido que se producirá será un olvido 'otro' que el antes padecido. $\mathrm{Y}$ es que existen diferentes modalidades de olvido. De esta forma Allouch nos habla de lethe-hypnos y de lethe-thanatos, y para hacerlo se apoya en Marcel Detienne citándolo en la página 27 de El sexo de la verdad:

¿Cuál es la naturaleza de ese Olvido? Ya no es la potencia negativa, el hijo de la noche que se opone a la Aletheia Luminosa. Lethe no es en este caso la oscuridad espesa; es la sombra, la sombra que ciñe la luz, la sombra de Aletheia. Hay que distinguir dos especies de Olvido que son entre sí como los gemelos Thanatos e Hypnos: si el primero es negro y si tiene 'un corazón de hierro, un alma de bronce, implacable, en su pecho', el segundo, Sueño, es blanco, 'tranquilo y dulce para los hombres [estas formulas son tomadas de la Teogonía de Hesiodo]. Al Olvido-Muerte se opone el Olvido-Sueño, al Olvido negativo responde el Olvido positivo. [...] Lethe ya no es el Hijo de la Noche sino la madre de las Khárites, de las 'visiones brillantes', de la alegría de los banquetes y de los 'efluvios centelleantes' (ganos) que surgen en los festines ceremoniales. Lethe acompaña a Eros y al dulce placer de las mujeres. (cursivas, paréntesis y mayúsculas del autor)

Allouch propone, y se lo propone al psicoanálisis, que será en la transferencia, como dimensión erótica donde estas posibilidades de creación ocurrirán, y plantea que esa será una forma de responder a las objeciones de Foucault cuando alertaba contra ese psicoanálisis que puede entenderse como una pastoral, ese psicoanálisis que entendía el olvido como un mero obstáculo y no como una dimensión creativa.

Marcelo Novas ${ }^{1}$

\section{Nota}

1. Licenciado en Psicología por la UdelaR, Magister en Psicología Clínica en la Facultad de Psicología de la UdelaR, Diplomado en Servicios de Salud, opción Psicoanálisis en la Facultad de Medicina de la UdelaR, docente del programa Psicoanálisis y Fronteras Disciplinares de Instituto de Psicología Clínica de la Facultad de Psicología de la UdelaR dirigido por la Dra. Ana Hounie y la Dra. Andrea Bielli, miembro de la línea de Investigación Enseñanza y Psicoanálisis (EnPsi), dirigida por la Dra. Ana Ma. Fernandez Caraballo, del Departamento de Enseñanza y aprendizaje del Instituto de Educación de la Facultad de Humanidades y Ciencias de la Educación (UdelaR). 


\section{Bibliografía}

Allouch, Jean. (1993). Letra por letra. Buenos Aires: Edelp.

Allouch, Jean. (1999). El sexo de la verdad. Córdoba: Edelp.

Colli, Giorgio. (2000). Introducción a Nietzsche. Valencia: Pre-textos.

Deleuze, Gilles. (2008). Nietzsche y la filosofía. Barcelona: Anagrama.

Díaz Genis, Andrea. (2008). El eterno retorno de lo mismo o el terror a la historia. Montevideo: Ediciones Ideas.

Foucault, Michel. (2008). La verdad y las formas jurídicas. Buenos Aires: Gedisa.

Freud, Sigmund. (1893a). Sobre el mecanismo psíquico de fenómenos histéricos: comunicación Preliminar. Buenos Aires: Amorrortu editores, tomo II.

Freud, Sigmund. (1901b). Psicopatología de la vida cotidiana. Buenos Aires: Amorrortu editores, tomo VI.

Freud, Sigmund. (1914d). Contribución a la historia del movimiento psicoanalítico. Buenos Aires: Amorrortu editores, tomo XIV.

Freud, Sigmund. (1914g). Recordar, repetir y reelaborar. Buenos Aires: Amorrortu editores, tomo XII.

Freud, Sigmund. (1918b). De la historia de una neurosis infantil. Buenos Aires: Amorrortu editores, tomo XVII.

Freud, Sigmund. (1919h). Lo ominoso. Buenos Aires: Amorrortu editores, tomo XVII.

Freud, Sigmund. (1920g). Más allá del principio del placer. Buenos Aires: Amorrortu editores, tomo XVIII.

Freud, Sigmund. (1925d). Presentación autobiográfica. Buenos Aires: Amorrortu editores, tomo XX.

Freud, Sigmund. (1937c). Análisis terminable e interminable. Buenos Aires: Amorrortu editores, tomo XXIII.
Todos los textos precedentemente citados de Freud fueron tomados de sus Obras Completas, publicadas por Amorrortu editores entre 1978 y 1981, con sucesivas reediciones.

Freud, Sigmund. (1994). Cartas a Wilhelm Fließ. Buenos Aires: Amorrortu editores.

Heidegger, Martín. (2005). Caminos de bosque. Madrid: Alianza.

Klossowski, Pierre. (2005). Nietzsche y el círculo vicioso. Buenos Aires: Caronte Filosofía.

Lacan, Jacques. (1964-1965). seminario inédito, Problemas cruciales para el Psicoanálisis, traducción de Ana María Gómez y Sergio Horacio Rocchetti, destinada a circulación interna, no revisada por su autor.

Lacan, Jacques. (1987). Escritos. México: Siglo XXI.

Nietzsche, Friedrich. (1984). Así habló Zaratustra. Madrid: ediciones Busma.

Nietzsche, Friedrich. (1997). Genealogía de la moral. México: Editorial Porrúa.

Nietzsche, Friedrich. (2004). Sobre verdad y mentira en sentido extramoral. Madrid: Tecnos.

Nietzsche, Friedrich. (2004). La gaya ciencia. Buenos Aires: Andrómeda.

Roudinesco, Elizabeth. (1994). Lacan. Buenos Aires: Fondo de cultura económica.

Varela, Gustavo. (2010). Nietzsche, una introducción. Buenos Aires: editorial Quadrata.

\section{(c) (i) (ㅇ)}

Esta obra está bajo una licencia de Creative Commons Reconocimiento - NoComercial - CompartirIgual (by-nc-sa) 